Check for updates

Cite this: J. Anal. At. Spectrom., 2021, 36,2617

Received 11th July 2021

Accepted 10th November 2021

DOI: $10.1039 / d 1 j a 00243 k$

rsc.li/jaas

\section{Fundamental studies on droplet throughput and the analysis of single cells using a downward- pointing ICP-time-of-flight mass spectrometer}

\author{
Thomas Vonderach (D) and Detlef Günther (DD*
}

\begin{abstract}
Capabilities of the downwardly oriented inductively coupled plasma mass spectrometer (ICP-MS) recently reported (Vonderach et al. 2021) were studied using a time-of-flight mass spectrometer (TOFMS) yielding benefits for the fast detection of short transient signals containing multi-element information. The previously reported sample inlet configuration for the analysis of microdroplets was equipped with two extra gas inlets for the supply of argon and helium, which enabled a more precise optimization of the sample introduction and operating conditions of the plasma. Furthermore, the sample supply system was operated at elevated temperatures to enhance the desolvation of the droplets prior to their introduction into the plasma. Transient droplet signals with frequencies of up to $1000 \mathrm{~Hz}$ were recorded for $74 \mu \mathrm{m}$ (diameter) sized droplets. The upper detectable droplet size was limited by the droplet generator used and was measured at $93 \mu \mathrm{m}$ (diameter). The droplets served as the transporter for biological cells so that the described setup could be used to analyze single cells. Mouse lung cells embedded into droplets were detected successfully according to their Cs droplet tracer, Ir nucleus marker, surface markers and the phosphorus content. Transient signals were recorded at a time resolution of $33 \mu$ in order to investigate the signal structure of single droplet-cell events containing multiple elements. Signals between 200-400 $\mu \mathrm{s}$ (FW base) and $\leq 100 \mu \mathrm{s}$ (FWHM) in duration were measured. To ensure that the droplet formation process did not affect the sampled cells, different types of cells were localized within the droplets using optical inspection directly after droplet formation and it was possible to observe that cells remained intact with random sampling. The results indicate that a downward-pointing ICP-MS in combination with the microdroplet-based approach can be considered as an alternative to commonly used ICP-MS systems for single cell analysis, and might be suitable for online coupling to flow cytometry.
\end{abstract}

\section{Introduction}

Nebulizers in combination with spray chambers as a sample introduction technique are still the "gold standard" for sampling in inductively coupled plasma mass spectrometry (ICP-MS) as they are easy to apply, robust and provide good reproducibility. ${ }^{2,3}$ However, as they produce highly polydispersive aerosols, limitations regarding sample transport efficiency are observed, especially when analyzing single particles or single, biological cells. In order to achieve high aerosol transport efficiencies, the nebulization process needs to produce droplets of less than $10 \mu \mathrm{m}$ in diameter. Much effort has been invested into the development of more efficient and robust spray systems in order to extend the capabilities. ${ }^{\mathbf{4 - 1 0}}$

Laboratory of Inorganic Chemistry, Department of Chemistry and Applied Biosciences, ETH Zurich, Vladimir-Prelog-Weg 1, 8093 Zurich, Switzerland. E-mail: guenther@ inorg.chem.ethz.ch

$\dagger$ Electronic supplementary information (ESI) available. See DOI: 10.1039/d1ja00243k
Sampling systems comprised of microfluidic systems, ${ }^{\mathbf{1 1}}$ for example microdroplet generators can be considered as an alternative sample introduction system for ICP-MS. The idea was first proposed in 1968 by Hieftje and Malmstadt, ${ }^{12,13}$ developed further by French, ${ }^{\mathbf{1 4}}$ and successfully applied to ICP spectrometry studies by Hieftje, ${ }^{15-20}$ Olesik, ${ }^{21-27}$ Farnsworth and Lazar, ${ }^{28-30}$ Houk $^{31}$ Niemax, $^{32-34}$ Günther ${ }^{35-39}$ and Engelhard. ${ }^{40}$ These studies revealed fundamental insights about processes such as droplet desolvation, particle vaporization as well as diffusion, matrix, and space-charge effects. ${ }^{1,22}$ Using monodisperse droplets has advantages over more common spray systems due to the discrete sample introduction that enables the determination of absolute detection efficiencies ${ }^{\mathbf{4 1}}$ and the quantification of nanoparticles..$^{32,35,42}$ However, it comes with other difficulties such as memory effects when the sample matrix is changed, clogging of the capillaries or air bubbles causing dispensing to stop, that had and still need to be resolved. Olesik ${ }^{22}$ and co-workers carried out multiple aerosol formation and transport studies and explained, why a sample supply system for monodisperse droplets requires an efficient desolvation system. Large droplets in the plasma lead to 
significant changes in the plasma conditions, which has an impact on sensitivity, precision, noise, accuracy, and polyatomic ion formation. Heated sample drop supply systems as reported by Olesik et $a .^{24}$ and Kaburaki et $a .^{43}$ or a lowtemperature, He-assisted desolvation system as developed by Gschwind et $a .^{35}$ were used to desolvate the droplets prior to their analysis within the plasma. As demonstrated by Koch et al. ${ }^{36}$ the use of an He-assisted desolvation system shows evaporation rates that are 3 times higher than using Ar-only sample carrier systems. Recently, Alavi et al. $^{\mathbf{4 4}}$ reported a droplet throughput of up to 2000 droplets per second using an optimized falling tube setup, which could only be realized upon heating the He carrier gas to $130{ }^{\circ} \mathrm{C}$. However, the experimental demonstration of such high-speed sample introduction into an ICP-MS has not been reported.

Not only droplet supply systems for monodisperse droplet sampling benefit from elevated temperatures, also spray chambers show an improved performance or other gains, e.g. improved sensitivity or reduction of polyatomic ion interferences when heated..$^{451}$ For example, in Mass Cytometry (MC), the CyTOF® instruments are equipped with heated spray chambers operating at temperatures up to $200{ }^{\circ} \mathrm{C} .{ }^{52,53}$ The system has proven itself as very practical for single cell analysis. In certain fields of application, MC has truly become a competing technique to Flow Cytometry (FC). ${ }^{54}$ Both techniques show multiplexing capabilities and are, nowadays, equally suitable for single cell analysis, but show some fundamental differences, which makes, depending on the experimental requirements and sample composition, one technique more suitable than the other. While MC is a destructive method, flow cytometers can be equipped with a sorting mechanism allowing the recovery of the cells after analysis. In MC, a cell suspension is nebulized obtaining transport efficiencies of 20$25 \%$ and cell throughputs up to 1000 cells per s (usually operated at 300-500 cells per $s$ to reduce the number of double events) have been reported. ${ }^{55}$ In contrast, FC instruments are equipped with a microfluidic system that generates monodisperse droplets via hydrodynamic focusing yielding recovery rates $>95 \%$ and a cell throughput of up to 25000 cells per $\mathrm{s}$ (highly application specific). ${ }^{55,56}$

At the moment, it remains unknown what the cell survival efficiency for nebulization techniques in the context of ICP-MS is and whether the transport via monodisperse microdroplets can be considered as a more gentle and confined cell transport technique. ${ }^{57-60}$

Studies have shown that the post-spray cell survival depends on the nebulizer design as well as on the cell type. ${ }^{61}$ Recently, Shigeta et al. ${ }^{\mathbf{2 2 , 6 3}}$ demonstrated successfully how monodisperse droplets could be used to study the element composition of 1-2 $\mu \mathrm{m}$-sized selenized yeast cells. However, the study was carried out using a sequential instrument, which did not provide multielement information from single cells. In another study, a microchip was used to generate droplets from cell suspensions, followed by analysis using an ICP-MS as reported by Verboket et al. ${ }^{64}$ The results indicate that regarding the achievable cell throughput, microfluidic systems can be considered as an alternative to spray systems, even though the development of high-throughput microfluidic devices for ICPMS applications is still pending. The use of monodisperse droplets as cell transporters, as it is used in FC, promoted further improvement of the simultaneous measurement capabilities and changes in the sample drop supply systems in order to pave the way for high-throughput single cell analysis. Therefore, the coupling of flow cytometry technology, for instance cell sorters, with a downward ICP-MS is, in principle, possible. An online coupling of the information received from the scatter experiment (FC) in combination with the information from mass spectrometry would yield greater information and the advantages of both techniques could be exploited. For instance, an online coupled system would allow to correlate the cell size with the antibody content directly on a cell-to-cell base, at least in a semi-quantitative fashion.

This study reports on the capabilities of a downwardpointing ICP-MS ${ }^{\mathbf{1 , 6 5}}$ using a TOF mass analyzer and a modified sample introduction system attached to a microdroplet generator operated at dispensing frequencies of up to $1000 \mathrm{~Hz}$. The downward orientation of the ICP, that was also reported for an optical emission spectroscopy (OES) system in ref. 66 recently, enables a gravity-assisted sampling of larger sized droplets that would be difficult to transport into horizontally oriented ICP systems. Droplet introduction was studied in dependence on droplet frequency, size and composition. Furthermore, monodisperse droplets were generated from cell suspensions and the ejected droplets transported the cells downward into the plasma. In order to confirm that the cells were still intact after droplet formation, single cells were observed within single water or phosphate-buffered saline (PBS) droplets, right after ejection from the capillary tip using optical inspection with a blue strobe LED and a CCD camera. The signal structures of the single cell events were investigated by recording ion signals of stained mouse lung cells with a time resolution of $33 \mu \mathrm{s}$.

\section{Experimental}

\section{Instrumentation and sample introduction system}

A schematic sketch of the current downward ICP-MS used is shown in Fig. 1. Technical details regarding the downward orientation of the ICP have been reported ${ }^{\mathbf{1}}$ and are summarized in Fig. S1. $\dagger$ The MS used in the earlier proof-of-concept study was replaced by a prototype time-of-flight (TOF) mass analyzer (TOFWERK AG, Thun, Switzerland \& ETH Zurich) that has the ELAN 6000/6100 interface allowing a direct coupling with the ICP source. Further technical details on the prototype TOFMS system can be found in Borovinskaya et al. ${ }^{67}$ and Schild et al. ${ }^{68}$ Monodisperse droplets were generated using a $20 \mu \mathrm{g} \mathrm{L}^{-1}$ multielement solution (dilutions from ICP reference standards from Inorganic Ventures and Merck) in $1 \% \mathrm{HNO}_{3}$ (sub-boiled $\mathrm{HNO}_{3}$ and high purity water, $18.2 \mathrm{M} \Omega \mathrm{cm}$, Millipore) using an autodrop pipette (microdrop technologies $\mathrm{GmbH}$, Norderstedt, Germany).$^{69}$ A piezo actuator emitted upon contraction a pressure wave through a quartz capillary that is filled with a sample solution so that a defined volume forms a droplet. The capillary was equipped with either a $30 \mu \mathrm{m}, 50 \mu \mathrm{m}$ or $70 \mu \mathrm{m}$ (diameter) sized nozzle. The Microdrop Dispensing System (MD-E-3000, 




Fig. 1 Schematic sketch of the modified sample droplet supply system is presented. A falling tube made of glass was complemented with two additional, serial laminar flow adapters at the lower part of the tube. The entire sample droplet supply system was covered by a heating tape and the introduced He gas was pre-heated using a heating tape wrapped around steel gas supply tubes. The He gas temperature within the falling tube was measured at approximately $90^{\circ} \mathrm{C}$.

microdrop technologies GmbH, Norderstedt, Germany) was used to switch between single and triple pulse mode and to adjust the voltage and width of the applied pulses at a selectable dispensing frequency. The triple pulse mode was used to produce smaller droplets than achievable in the single pulse mode for the corresponding nozzle. Accordingly, it was applied to produce $80 \mu \mathrm{m}$ (diameter) sized droplets from a $70 \mu \mathrm{m}$ nozzle. Further experimental details are provided in Table 1.

The droplets were observed several hundred micrometers below the autodrop pipette glass capillary tip using a CCD camera (Ximea, xiQ, MQ013MG-E2) and stroboscopic light illumination. After passing the MDG capillary, the droplets were guided through an in-house designed falling tube made of glass pointing downwardly into the injector and further into the plasma as shown in Fig. 1. Two laminar flow adapters were serially attached at the lower end of the falling tube thus the entire sample drop supply system was equipped with three gas inlets. The He gas was introduced from the top and the inlet was located above the tip of the pipette glass capillary (gas inlet 1). Furthermore, He was supplied through the upper laminar flow adapter (gas inlet 2) and Ar was added through the lower laminar flow adapter (gas inlet 3). Heating tape was wrapped around the sample drop supply system and around the steel tubes of the He gas supply, which allowed the setup to be operated at elevated temperatures. An estimation of the gas temperature within the falling tube using a platinum wire as temperature sensor was approximately $90{ }^{\circ} \mathrm{C}$. Further operational parameters are provided in Table 2.

Mouse lung cells were provided by the research group of $\mathbf{M}$. Kopf, Institute of Molecular Health Sciences, ETH Zurich, in the context of a collaboration. The studies that included animals were carried out according to the institutional guidelines, the Swiss federal regulations and has been approved by the animal ethics committee of Kantonales Veterinärsamt, Zürich, Switzerland.

\section{Studies of the droplet throughput and droplet size}

$74 \mu \mathrm{m}$ droplets were introduced into the plasma at frequencies ranging from 100 to $1000 \mathrm{~Hz}$. Time-resolved mass spectra were collected continuously in single "segments" at a spectral averaging rate of $5.56 \mathrm{kHz}$ (180 $\mathrm{s}$ s per spectrum) for $184 \mathrm{~ms}$ (1024 spectra). Between segments, a variable time delay (0.5-1 s) was required to write data to the disc storage. For the analyses presented, droplet signals were collected across six segments for a total continuous analysis time of $1.10 \mathrm{~s}$. Analogously to the previous studies, droplets of different sizes were analyzed, e.g. $54 \mu \mathrm{m}$ and $73 \mu \mathrm{m}$ sized droplets at $400 \mathrm{~Hz}$, and, $80 \mu \mathrm{m}$ and 93 $\mu \mathrm{m}$ sized droplets at $200 \mathrm{~Hz}$, respectively.

\section{Single cell acquisition}

Monodisperse droplets were dispensed at a frequency of $100 \mathrm{~Hz}$ transporting single cells into the plasma. Droplet and cell

Table 1 Nozzle diameter and corresponding droplet diameter sizes are listed. Note, that the size of the ejected droplet depends on the nozzle diameter and the selected pulse mode

\begin{tabular}{llll}
\hline Autodrop pipette & Nozzle size $[\mu \mathrm{m}]$ & Pulse mode & Droplet size $[\mu \mathrm{m}]$ \\
\hline AD-KH-501-L6 SN: 129 & 30 & Single & $55 \pm 1.5 \mu \mathrm{m}$ \\
AD-KH-501 SN: 82 & 50 & Single & $74 \pm 1.5 \mu \mathrm{m}$ \\
AD-KH-501 SN: 109 & 70 & Triple & $80 \pm 1.5 \mu \mathrm{m}$ \\
& & Single & $93 \pm 1.5 \mu \mathrm{m}$
\end{tabular}


Table 2 Typical operating conditions for the sample droplet supply system and the ICP-TOFMS are summarized

\begin{tabular}{ll}
\hline $\begin{array}{l}\text { Operational } \\
\text { parameters }\end{array}$ & Value \\
\hline He flow (upper) & $0.4 \mathrm{~L} \mathrm{~min}^{-1}$ \\
He flow (lower) & $0.5 \mathrm{~L} \mathrm{~min}^{-1}$ \\
Ar flow & $0.3 \mathrm{~L} \mathrm{~min}^{-1}$ \\
Ar auxiliary gas flow & $0.9 \mathrm{~L} \mathrm{~min}^{-1}$ \\
Ar plasma gas flow & $14.2 \mathrm{~L} \mathrm{~min}$ \\
ICP power & $1550 \mathrm{~W}$ \\
Einzel lens & $11.4 \mathrm{~V}$ \\
Sampling depth & $11 \mathrm{~mm}$ \\
Injector diameter & $1.5 \mathrm{~mm}$
\end{tabular}

events were acquired using the trigger-mode, which allowed the recording of the events with a time resolution of $33 \mu \mathrm{s}$. To measure the arrival of individual droplets, Cs was used as droplet tracer. Thus, according to the Cs ion signal and a userdefined threshold an event was either recorded or discarded. ${ }^{70}$ In later studies, mass spectra were recorded at a spectral averaging rate of $333 \mathrm{~Hz}$, which corresponds to $3 \mathrm{~ms}$ mean time, continuously for a 2 min acquisition time per run. Cell sample preparation and the staining procedure is further described in the ESI. $\dagger$

\section{Data processing and analysis}

Droplet images were acquired randomly and further processed using the open-source software ImageJ (W. S. Rasband, US National Institutes of Health, Bethesda, MD, USA). ${ }^{36}$ A LabVIEW® (Version 10.0.1, National Instruments Corp., Austin, TX, USA) program was used to read and process the TOF data that was stored in aforementioned "segments". Python 3.7 was further used for data processing and visualization. Amadine (1.0.7, BeLight software Ltd, Odessa, Ukraine) was used to draw a schematic visualization of the experimental setup. Note, that the provided ion signals are given in counts which refers to estimated numbers of counts derived from the recorded voltages and the single-ion signal (SIS) value that had to be determined according to the applied microchannel plate (MCP) detector settings. ${ }^{71}$

\section{Results \& discussion}

\section{Time-resolved droplet measurements}

As previously reported, a sample droplet throughput of $1000 \mathrm{~Hz}$ was achieved using a quadrupole based downward-pointing ICP-MS. ${ }^{1}$ However, as the acquisition capabilities showed temporal limitations, it was not possible to provide timeresolved single droplet signals for dispensing frequencies up to $1000 \mathrm{~Hz}$. Therefore, the quadrupole mass analyzer was replaced by a time-of-flight mass analyzer, which was equipped with faster detection electronics that allowed to study individual droplets on their multi-element composition. $74 \mu \mathrm{m}$ sized monodisperse droplets were dispensed up to a droplet production frequency of $1000 \mathrm{~Hz}$, in steps of $100 \mathrm{~Hz}$. The droplet time traces for ${ }^{103} \mathrm{Rh}^{+},{ }^{175} \mathrm{Lu}^{+}$and ${ }^{193} \mathrm{Ir}^{+}$are shown in
Fig. 2 providing $30 \mathrm{~ms}$ time sections. The single droplet events were acquired with a time resolution of $180 \mu$ s.

Upon visible and statistical inspection of the single droplet signals in Fig. 2, a peak-to-peak ion signal variation can be observed. Assuming that a single droplet event gives rise to a minimum duration of $200 \mu \mathrm{s}$, every droplet event contains at least 2 acquisition points. Thus, the integration of the single peak signals obtaining the total number of ion counts per event is required in order to be able to make peak-to-peak comparisons. The relative standard deviation (RSD) and jitter values are presented in Fig. 3 and are discussed.

The droplet throughput studies whose results were summarized in Fig. 2 were carried out maintaining the ICP power at $1550 \mathrm{~W}$, without changing the gas flows or any other parameters that influence the plasma conditions. The parameters were optimized for the highest sensitivity and ion signal stability yielding a He gas flow that was significantly higher $(0.4$ $+0.5 \mathrm{~L} \mathrm{~min}^{-1}$ ) than the Ar gas flow $\left(0.3 \mathrm{~L} \mathrm{~min}^{-1}\right)$. As the droplet frequency was increased from $100 \mathrm{~Hz}$ to $1000 \mathrm{~Hz}$, the amount of water that was introduced into the plasma per time unit covered a change by one order of magnitude, that is from $20 \mathrm{~nL} \mathrm{~s}^{-1}$ to $200 \mathrm{~nL} \mathrm{~s}{ }^{-1}$. However, the absolute amount of water vapor introduced into the ICP was still low and a strong cooling leading to a tremendous performance degradation was neither to be expected nor observed in this study. As reported in earlier studies, the presence of small amounts of water in an analytical ICP enhanced the thermal conductivity, and thus, the energy transfer processes. ${ }^{72,73}$

As noted by Chan and Hieftje, ${ }^{15,16}$ a single microdroplet leads to a perturbation in the ICP. In their studies, they were able to observe plasma shrinkage due to a thermal pinch as well as local cooling and reheating of the plasma as consequences of a vaporization of the droplet. The reheating appeared to be a very fast process ( $\mu$ s time regime), so that the temperature was restored quickly from an original strong local cooling of the plasma and even reached a higher value than observed for the steady state. Although the temperature was recovered quickly, the plasma did not return to its steady-state equilibrium in the same span of time and the heating process was found to last several ms (50 $\mu \mathrm{m}$ microdroplets were investigated) which led to the overall conclusion that the relaxation proceeds slowly when compared to the time between consecutive droplets dispensed at dispensing frequencies in the range of several hundred $\mathrm{Hz}$ (studied here). The investigation regarding the alteration of the plasma impedance upon the perturbation of the droplet yielded the result that a relaxation-time of approximately $10 \mathrm{~ms}$ was needed to return to the steady-state level. As in this study, significantly bigger droplets were used, that is $74 \mu \mathrm{m}$ instead of $50 \mu \mathrm{m}$, even a slightly longer relaxation time could be expected. Based on these results reported in ref. 22 and 23, it can be concluded that in none of these studies whose results are summarized in Fig. 2, the plasma was able to return to a nonperturbed, i.e. steady-state level before the arrival of the next droplet. This means that every frequency reflects a different perturbation state of the plasma. Recorded signals were stable for a given dispensing rate, which indicated perturbed but still 

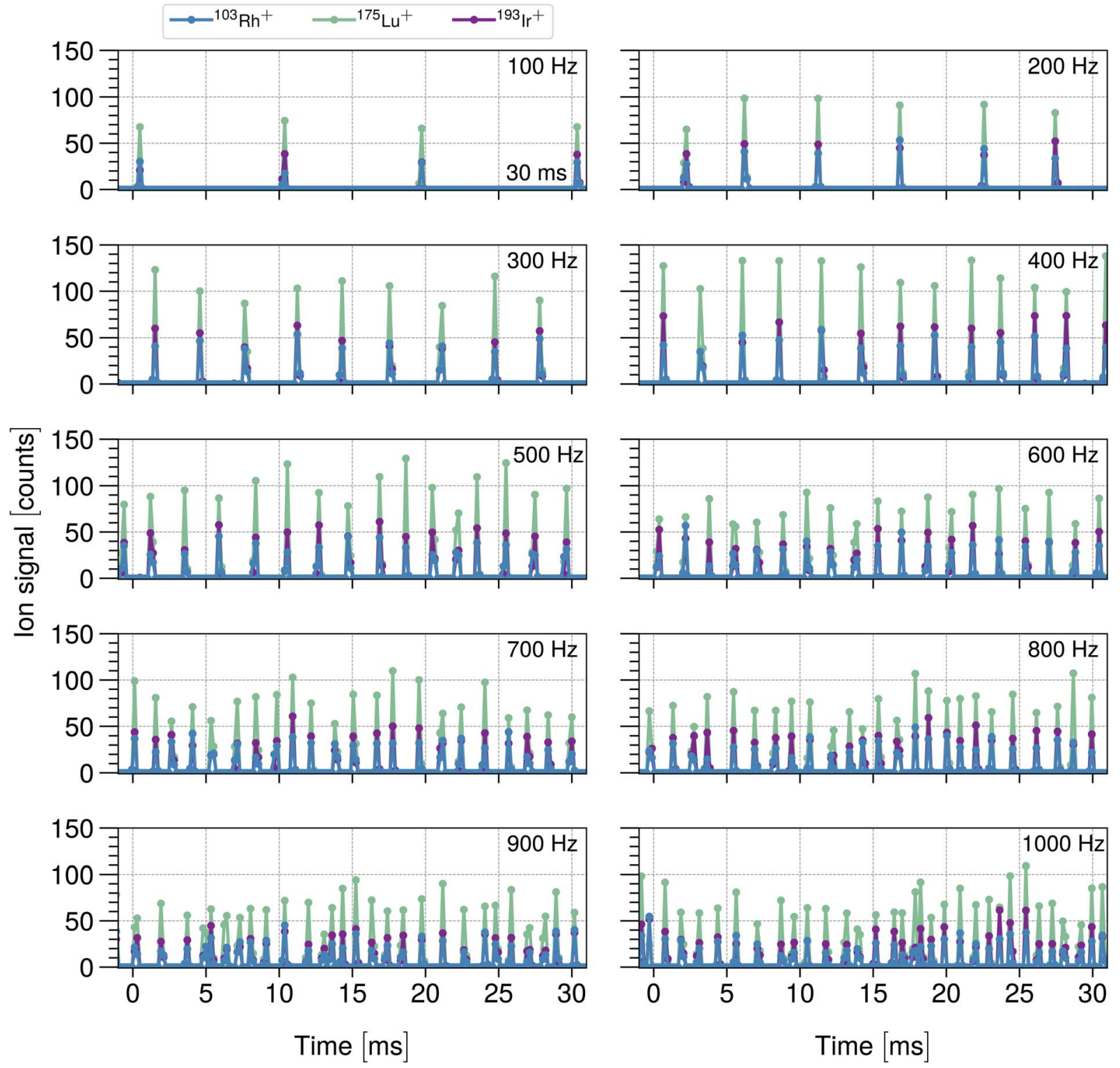

Fig. 2 Shows 30 ms time sections of transient ${ }^{103} \mathrm{Rh}^{+},{ }^{175} \mathrm{Lu}^{+}$and ${ }^{193} \mathrm{Ir}^{+}$ion signals originating from $74 \mu \mathrm{m}$ droplets up to droplet dispensing frequencies of $1000 \mathrm{~Hz}$. A $20 \mu \mathrm{g} \mathrm{L} \mathrm{L}^{-1}$ multi-element solution in $1 \% \mathrm{HNO}_{3}$ was used to produce the droplets while the mean analyte mass per droplet was determined to be $4.3 \pm 0.3 \mathrm{fg}$ for Rh and $4.04 \pm 0.24 \mathrm{fg}$ for Lu and Ir (see Table S1 $\uparrow$ ).

reproducible plasma conditions even though the delay between two consecutive droplets fell below the ICP's relaxation time.

Within these studies, the highest sensitivity was obtained for a droplet dispensing frequency of $400 \mathrm{~Hz}$, increasing or decreasing the droplet frequency led to a sensitivity reduction of up to a factor of 2 towards $100 \mathrm{~Hz}$ and $1000 \mathrm{~Hz}$, respectively. Despite the dispensing frequency-dependent perturbation states, an axial as well as radial shift of the vaporization point of the droplet within the plasma upon dispensing frequency change could explain the observed sensitivity differences. A frequency-specific and accurate optimization of the plasma comprising the adjustment of gas flows, ICP power, sampling depth and Einzel lens voltage could compensate for the change in sensitivity.
The mean oxide ratios were determined to be $0.2 \%$ for $\mathrm{ThO}^{+} / \mathrm{Th}^{+}$and $0.2 \%$ for $\mathrm{CeO}^{+} / \mathrm{Ce}^{+}$at $100 \mathrm{~Hz}$ and increased with increasing dispensing frequency up to $1.1 \%$ for $\mathrm{ThO}^{+} /$ $\mathrm{Th}^{+}$and $0.7 \%$ for $\mathrm{CeO}^{+} / \mathrm{Ce}^{+}$at $1000 \mathrm{~Hz}$. The low oxide ratios for $\mathrm{ThO}^{+} / \mathrm{Th}^{+}$as well as for $\mathrm{CeO}^{+} / \mathrm{Ce}^{+}$indicated a high plasma temperature and minimized analyte signal losses due to oxide formation. ${ }^{74}$

Note, that water vapor from the desolvated droplet arrives earlier in the plasma as the corresponding droplet, because it gets accelerated faster. ${ }^{15}$ That the formation of oxides increased for higher dispensing frequencies could be explained by the fact that a higher amount of water vapor and thus, higher amount of oxygen was present in the plasma which increased the likelihood of analyte oxide formation. 
(a)

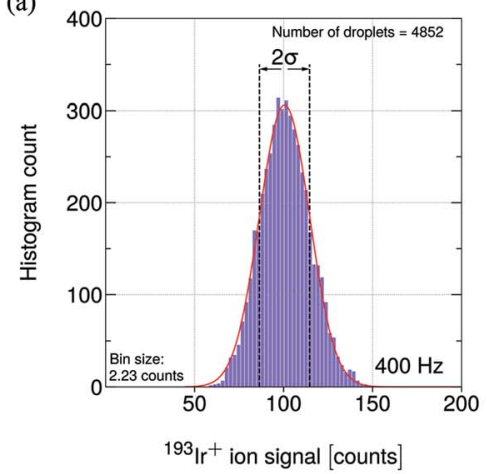

(b)

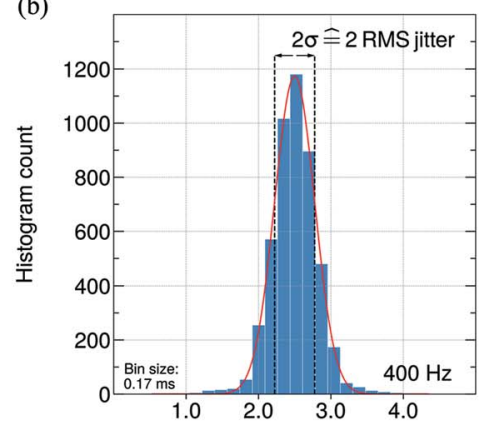

Droplet-to-droplet arrival time [ms]

(c)
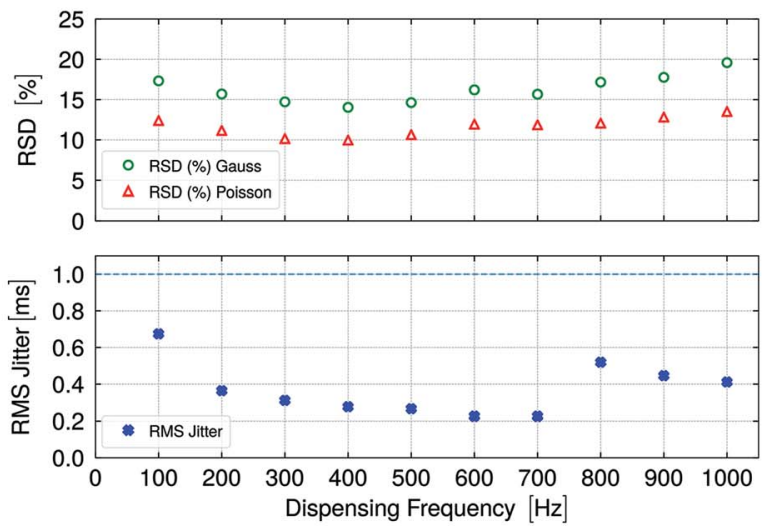

Fig. 3 The $\mathrm{Ir}^{+}$ion signal distribution (a) and the droplet-to-droplet arrival time distribution (b) are shown for the $400 \mathrm{~Hz}$ data set exemplarily. The RMS jitter corresponds to one relative standard deviation obtained for the Gaussian distribution of the droplet-to-droplet arrival time. The ideal, that is zero-jitter arrival time is $2.5 \mathrm{~ms}$ at the dispensing frequency of $400 \mathrm{~Hz}$. The relative standard deviations $(\sigma, \mathrm{RSD})$ of the mean $\mathrm{Ir}^{+}$ion signals and calculated RSDs based on Poisson counting statistics (in \%) for different droplet dispensing frequencies are shown in (c) in the upper graph. The obtained root mean squared (RMS) jitter values (calculated based on the $\mathrm{Ir}^{+}$ion signals) for the sample supply system as a function of the droplet dispensing frequency are presented in (c) in the lower graph. The measured ion signal variations approached the calculated Poisson-Gauss approximations and the determined RMS jitter values are below the $1 \mathrm{~ms}$ limit so that the resolution of single droplet events at $1000 \mathrm{~Hz}$ was possible. Note, even though single droplet events could be resolved in time, double droplet events (two droplets within $180 \mu \mathrm{s}$ ) occurred.

Also, Flamigni et $a l .^{39}$ reported increased oxide formation upon the addition of water vapor switching the conditions from dry to wet plasma conditions.
The TOF instrument was equipped with an Einzel lens whose voltage was set manually to a fixed value (no auto lens function was available). In this study, the voltage was set to $11.4 \mathrm{~V}$, which optimized the ion signal for the higher mass range. Accordingly, the sensitivity for $\mathrm{Rh}$ was expected to be significantly lower than for Ir, which was observed for the ion signals displayed in Fig. 2. The selection of Lu and Ir can be explained as follows: firstly, it is expected that only a small mass bias would occur depending on the optimization of the Einzel lens, because the $\mathrm{m} / \mathrm{z}$ difference is small $(\leq 20)$. Secondly, the analyte-plasma interactions are not identical, because two elements were compared, which have a significantly different first ionization potential $(5.4 \mathrm{eV}$ for $\mathrm{Lu}$ and $9.1 \mathrm{eV}$ for Ir) and other differing physical parameters such as heat of vaporization, boiling point, thermal conductivity and density (see Table S2 $\dagger$ ). In Fig. 4, the $\mathrm{Lu}^{+} / \mathrm{Ir}^{+}$ratios are shown as a function of the droplet dispensing frequency and a detailed discussion follows.

The relative standard deviation $(\sigma, \mathrm{RSD}, \%)$ values shown in Fig. 3c (upper graph) for $\mathrm{Ir}^{+}$ion signals were obtained from a Gauss-fit of the acquired droplet data which is shown exemplarily for the $400 \mathrm{~Hz}$ data set in Fig. 3a. The RSD (\%) Poisson values in Fig. $3 \mathrm{c}$ were calculated using the obtained mean value from the Gauss-fit.

The root mean squared (RMS) jitter values for the recorded $\mathrm{Ir}^{+}$ion signals are shown in Fig. 3c (lower graph) as a function of the droplet dispensing frequency. Fig. $3 \mathrm{~b}$ shows the distribution of the droplet-to-droplet arrival times exemplarily for the $400 \mathrm{~Hz}$ data set which was fitted with a Gaussian. Note, that the RMS jitter is defined as one relative standard deviation and the zerojitter droplet-to-droplet arrival time is $2.5 \mathrm{~ms}$ for the dispensing frequency of $400 \mathrm{~Hz}$.

Each data point was derived from a data set comprised of up to several thousands of droplet events. The obtained RSD (\%) Gauss values were close to the calculated RSD (\%) Poisson values indicating that the studies were carried out close to the instrument's optimum performance. ${ }^{71,75,76}$ Measured RSD (\%) values higher than from Poisson statistics predicted values indicate other sources of uncertainty, which could originate from droplet-plasma interactions or from a deviation of the droplet-to-droplet size. In comparison, the determined RSD (\%) values of $14 \%$ to $20 \%$ are in the same range as reported in other studies. ${ }^{35,67,77}$

According to Poisson statistics, the RSD (\%) Poisson values depend on the ion mean value, that is the RSD (\%) values increase when the mean signal decreases. The lowest RSD (\%) value was obtained at $400 \mathrm{~Hz}$. The measured RSD (\%) Gaussian values follow the scatter pattern of the calculated RSD (\%) Poisson values while a slight deviation regarding a larger RSD (\%) value difference for $1000 \mathrm{~Hz}$ was obtained. The larger variation in the ion signal and, thus, the broader ion signal distribution could originate from shorter recovery time of the perturbed plasma at $1000 \mathrm{~Hz}$ (when compared with the recovery times at lower frequencies) as well as axial and radial shifts of the vaporization point of the droplet within the plasma. ${ }^{15,24}$

Considering the time traces in Fig. 2 and the determined RMS jitter shown in Fig. 3, the highest jitter value of approximately 0.7 ms was obtained for $100 \mathrm{~Hz}$, which can be attributed to the 
plasma conditions as well as radial and axial shift of the vaporization point within the plasma. Significantly lower jitter values were obtained for frequencies between $200 \mathrm{~Hz}$ and $700 \mathrm{~Hz}$ with values between $0.2 \mathrm{~ms}$ and $0.4 \mathrm{~ms}$. Frequencies between $800 \mathrm{~Hz}$ and $1000 \mathrm{~Hz}$ yielded jitter values between $0.4 \mathrm{~ms}$ and $0.6 \mathrm{~ms}$. In order to resolve the droplet ion signals at $100 \mathrm{~Hz}$, jitter values $<10$ ms could still be tolerated. As a jitter of $0.7 \mathrm{~ms}$ was measured, which is one order of magnitude below the limit, the jitter played merely a minor role regarding data acquisition. At higher frequencies, e.g. $1000 \mathrm{~Hz}$, the jitter value has to be taken into account as a major limitation. Notably, the measured RMS jitter values were significantly below the $1000 \mathrm{~Hz}$ limit of $1 \mathrm{~ms}$ (dashed line) so that the single droplet events were still fully resolved in time. Importantly, with increasing frequency, the occurrence of double events (two droplets within $180 \mu$ s of each other) can become more likely. Up to $600 \mathrm{~Hz}$, the occurrence rate of double events remained below $1 \%$. However, the rate increased with increasing dispensing rate up to $1.6 \%$ for $700 \mathrm{~Hz}, 6.5 \%$ for $800 \mathrm{~Hz}, 6 \%$ for $900 \mathrm{~Hz}$ and $8.2 \%$ for $1000 \mathrm{~Hz}$, respectively. Note, the signal optimization for $1000 \mathrm{~Hz}$ droplet throughput was difficult to establish since there are many parameters and sources that could influence the occurrence of double events, e.g. the plasma optimization, the sample supply system geometry, gas dynamics, droplet velocity or instabilities in the droplet formation process could influence the trajectory of the droplet and the ionization process in the plasma.

Fig. 4 shows the $\mathrm{Lu}^{+} / \mathrm{Ir}^{+}$ion signal ratios as a function of the dispensing frequency (lower graph). The mean ratio was determined to be $1.29 \pm 0.03$ indicated by the horizontal, dashed line. The corresponding RSD (\%) (upper graph) was derived by error propagation.

Stable signal ratios for the two elements, Lu and Ir, that possess different physical parameters, especially in terms of the first
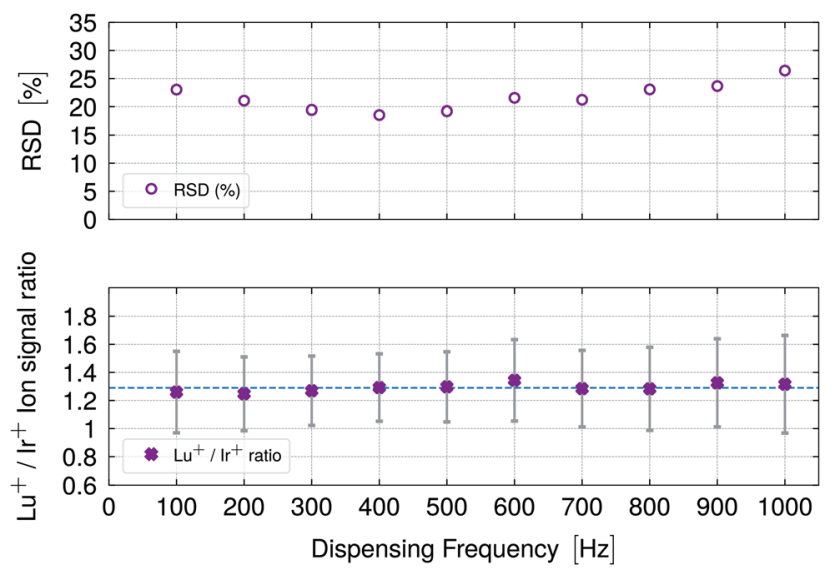

Fig. 4 The lower graph shows $\mathrm{Lu}^{+} / \mathrm{Ir}^{+}$ion signal ratios with standard deviations derived by error propagation for different droplet dispensing frequencies. The dashed line indicates the mean ratio for all frequencies which was determined to be $1.29 \pm 0.03$. The stable ion signal ratios did not indicate any frequency-dependent frequency dependent and element-specific reduction of the ionization capabilities of the plasma. The upper graph provides the RSD (\%) values as a function of the dispensing frequency following the same pattern as observed in Fig. 3. ionization potential, were measured. As discussed, v.i., the introduction of microdroplets into the plasma caused frequencydependent perturbations. However, even if the plasma was in a perturbed state at the time of the analysis, it did not influence the ionization capabilities in such a way that elements with a high first ionization potential would be ionized less efficiently than those with a significantly lower first ionization potential. The recorded ion signals and the obtained signal ratios indicate stable plasma conditions throughout the studies given the difference in the amount of water added to the plasma.

To study the influence of the droplet size, that is, the analyte mass on the ionization efficiency in detail, droplets of different sizes were introduced into the plasma using the same sample solution. Fig. 5 highlights the $\mathrm{Ir}^{+}$ion signal response versus the Ir analyte mass for four different droplet sizes (diameter), 55 $\mu \mathrm{m}, 74 \mu \mathrm{m}, 80 \mu \mathrm{m}$ and $93 \mu \mathrm{m}$. Three different autodrop pipettes equipped with a $30 \mu \mathrm{m}, 50 \mu \mathrm{m}$ and $70 \mu \mathrm{m}$ (diameter) nozzle size, were tested. Thus, $55 \mu \mathrm{m}$ sized droplets ( $30 \mu \mathrm{m}$ nozzle), $74 \mu \mathrm{m}$ sized droplets $(50 \mu \mathrm{m}$ nozzle) and $93 \mu \mathrm{m}$ (70 $\mu \mathrm{m}$ nozzle) were obtained when single pulses were employed. $80 \mu \mathrm{m}$ sized droplets $(70 \mu \mathrm{m}$ nozzle) were obtained when triple pulses were applied. Further details are shown in Table 1.

Increasing the droplet size and thus, the analyte mass yielded a linear increase of the mean ion signal as indicated by the regression line in Fig. 5. Notably, the analytes in the larger droplets $(80 \mu \mathrm{m}$ and $93 \mu \mathrm{m})$ were as efficiently ionized as the ones in the smaller droplets $(55 \mu \mathrm{m}$ and $74 \mu \mathrm{m})$. A single point in the plot represents the mean with its corresponding relative standard deviations resulting from a Gaussian fit consisting of a data set of 3000 to 7000 single droplet signals.

Stable $\mathrm{Lu}^{+} / \mathrm{Ir}^{+}$ratios were obtained for the different droplet sizes (see Fig. S1†) and the values are in agreement with the ratios shown in Fig. 4. This suggests that an efficient drying and ionization process had occurred. In order to keep the amount of water introduced into plasma per time unit within limits, and thusly, the plasma conditions comparable, the $55 \mu \mathrm{m}$ and $73 \mu \mathrm{m}$ droplets were dispensed at $400 \mathrm{~Hz}$ and the $80 \mu \mathrm{m}$ and $93 \mu \mathrm{m}$ droplets at $200 \mathrm{~Hz}$ obtaining a minimum water intake of $33 \mathrm{~nL}$ $\mathrm{s}^{-1}$ and a maximum intake of $84 \mathrm{~nL} \mathrm{~s}^{-1}$. Mean oxide ratios between 0.22 to $0.28 \%$ for $\mathrm{CeO}^{+} / \mathrm{Ce}^{+}$and 0.4 to $0.8 \%$ for $\mathrm{ThO}^{+} / \mathrm{Th}^{+}$ were measured which confirmed comparable plasma temperatures throughout the different studies. Note, that the autodrop pipette had to be exchanged between the studies in order to alter the droplet size. As every autodrop pipette required distinct parameters regarding pulse voltage and width in order to produce droplets, the droplet velocities depended on the dispenser unit used, which would have required individual optimization conditions for every single measurement, especially with regard to the applied gas flows. Therefore, small difference in the water uptake, variations in droplet velocity, small radial deviation of the vaporization point of the droplet, as well as the uncertainty due to the estimation of the droplet size would explain the deviation of the data values from the regression line.

Currently, the maximum droplet size and frequency is limited by the capabilities of the autodrop pipette and depend highly on the individual pipette. Notably, the modified sample droplet supply system for the downward ICP-MS can cope with 


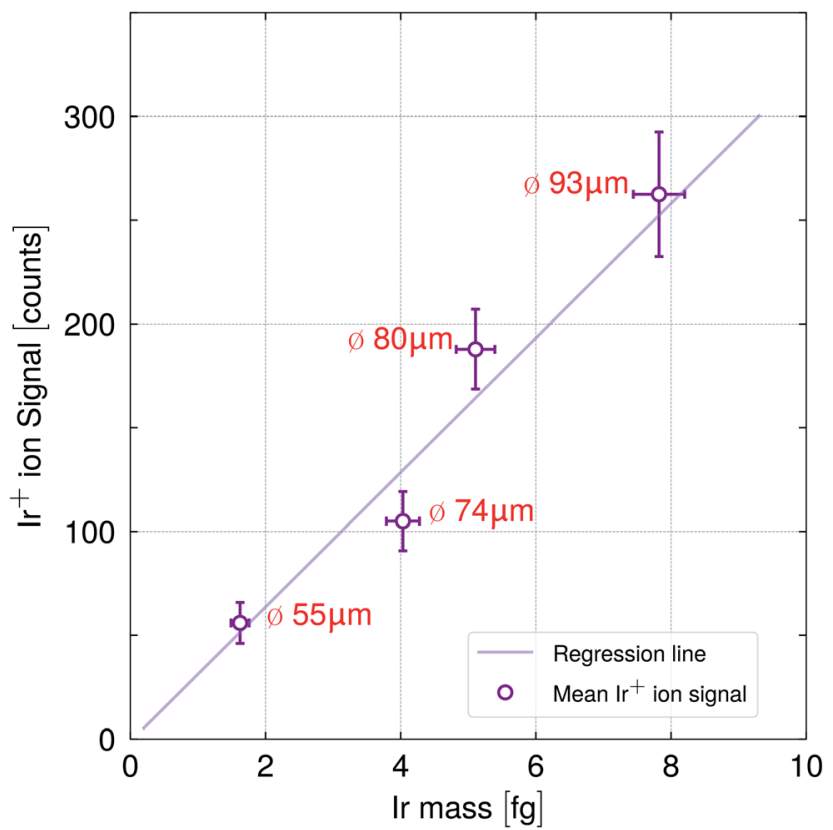

Fig. 5 Highlights the $\mathrm{Ir}^{+}$ion signal response with relative standard deviations as a function of the Ir mass for four different droplet sizes. The regression line $\left(R^{2}=0.9\right)$ indicates the linear relationship between the ion signal and the analyte mass.

single droplets up to a size of $93 \mu \mathrm{m}$, which has, to our knowledge, not been previously reported.

Considering the actual data and performance of the sample supply system, it is expected that even a $100 \mu \mathrm{m}$ (or larger) droplet containing a $20 \mu \mathrm{g} \mathrm{L} \mathrm{L}^{-1}$ multi-element solution would be sufficiently dried, vaporized, atomized and ionized. The $93 \mu \mathrm{m}$ droplet was produced using an autodrop pipette equipped with a $70 \mu \mathrm{m}$ nozzle which is, at the same time, matching the low end of the nozzle diameter in commercially available flow cytometers (typical nozzle diameters are $70,85,100$, up to $200 \mu \mathrm{m}),{ }^{78}$ approaching the large droplet sizes obtained in flow cytometry outputs.

\section{Time-resolved cell measurements}

This study set its main focus on the development of a suitable microdroplet-cell transport system and the presented results are indicative as proof of concept for the instrument geometry. To investigate the cell stability during droplet formation and transport, cells that were embedded in droplets were inspected optically. Various cell suspensions were sampled into the autodrop pipette's glass capillary equipped with a $50 \mu \mathrm{m}$ nozzle. The emitted droplets (approximately 70-74 $\mu \mathrm{m}$ ) were illuminated using a blue strobe LED and observed with a camera. Not only could the droplet formation and shape be observed, but it was possible to visualize and identify single cells within the droplets which is shown in the presented photographs in Fig. 6.

The stained human cells did not appear as perfectly round spheres, rather only approximating spheres. The mouse spleen cells that were resuspended in PBS were still alive and appeared to be slightly opaque and were shaped as almost perfectly round spheres.

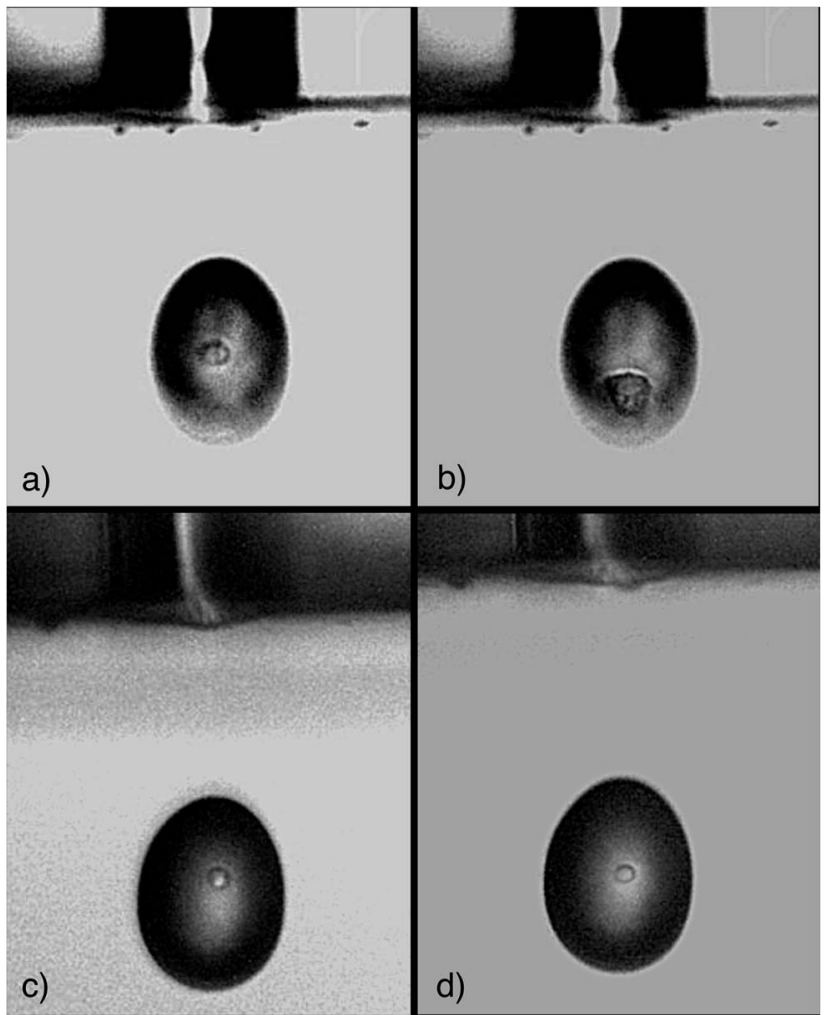

Fig. 6 Provides four different photographs of a single cell in a droplet (70-74 $\mu \mathrm{m})$. In (a) and (b) fixed and with metal-tagged antibodies stained human cells resuspended in water, PBMC and A375, respectively, and in (c) and (d) live mouse spleenocytes resuspended in PBS are shown. Note, that the photographs were taken immediately after droplet formation as the initial oval shape of the droplet allowed better illumination of a cell.

As the cell staining, that is the fixation of cells, leads to structural changes in the cells' proteins, which might have an impact on the stability of cells, live cells were resuspended in PBS for comparison. Stained cells in water as well as living cells in PBS could be observed within the droplets and no visible damage such as cell rupture or the presence of cell fragments, was observed. Note, that the pictures were taken randomly and not every single cell sampled into a droplet, could be inspected. Therefore, this is not a demonstration of the absence of any potential cell damage due to the emitted pressure wave. However, the number of cells inspected yields the conclusion that damage is not frequent.

The implementation of a light scatter experiment as provided in fluorescence-activated cell sorting (FACS) instruments prior to the element analysis would allow distinguishing of intact from shattered or fragmented cells. The purpose of using a FACS device would, firstly, yield more information as multiple fluorescence markers could be included, secondly, it would enable a more accurate interpretation of the observed transients and thirdly, this would allow the investigation of the rate of damaged cells in the sample suspension.

In order to better understand the cell-droplet-plasma interaction and to gain information about the duration of the 

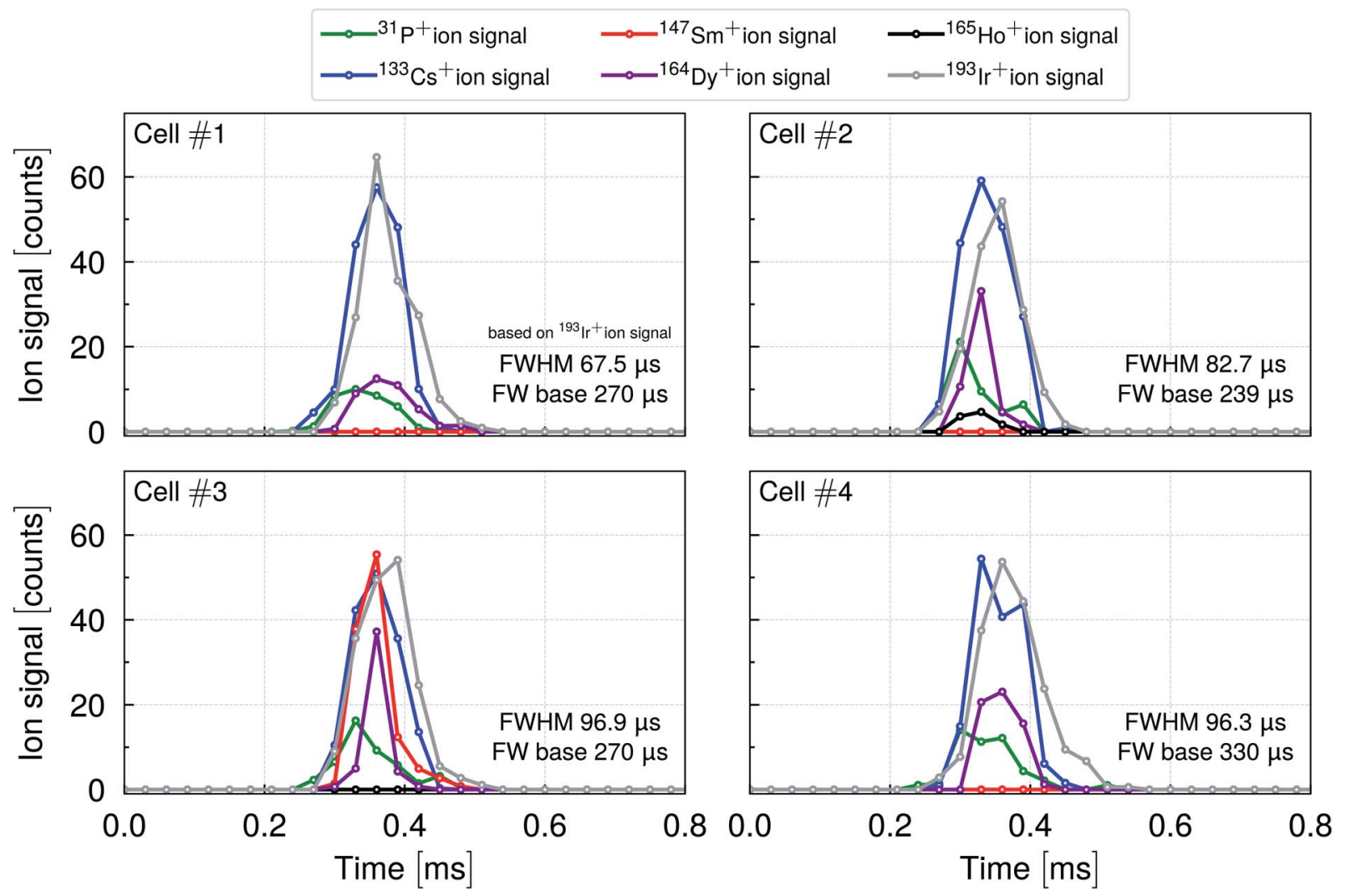

Fig. 7 Shows transient ion signals of cells transported by droplets. Cell and droplet event occurred almost simultaneously which is indicated by the superimposed ${ }^{133} \mathrm{Cs}^{+}$and ${ }^{193} \mathrm{Ir}^{+},{ }^{164} \mathrm{Dy}^{+}$and ${ }^{31} \mathrm{P}^{+}$(for some cells ${ }^{165} \mathrm{Ho}^{+}$, and ${ }^{147} \mathrm{Sm}^{+}$) ion signals. The ${ }^{133} \mathrm{Cs}^{+}$and ${ }^{193} \mathrm{Ir}^{+}$ion signals show approximately the same duration whereas the ${ }^{31} \mathrm{P}^{+}$and surface marker signals tend to be shorter.

transient ion signal of a cell within a droplet, data was recorded with a time resolution of $33 \mu \mathrm{s}$, which was the shortest possible time resolution provided by the TOF instrument used. Mouse lung cells (CD45+ enriched) were stained with ${ }^{164} \mathrm{Dy},{ }^{165} \mathrm{Ho}$ and ${ }^{147} \mathrm{Sm}(\mathrm{CD} 45+, \mathrm{CD} 4+, \mathrm{CD} 11 \mathrm{~b}+)$ conjugated antibodies in order to label surface proteins. Ir intercalator was used to mark the DNA in the cell nuclei. Cs served as a droplet tracer indicating the arrival of the droplet while the ${ }^{193} \mathrm{Ir}^{+},{ }^{164} \mathrm{Dy}^{+},{ }^{165} \mathrm{Ho}^{+}$, and ${ }^{147} \mathrm{Sm}^{+}$ion signals were used to track the single cell events. Four representative events are shown in Fig. 7.

In all the cell-droplet events shown, the surface marker ion signals, DNA ion signals and droplet ion signals occurred approximately at the same time. As $\mathrm{P}$ is an essential element of the cell and also present in the conjugated-antibodies used, ${ }^{31} \mathrm{P}^{+}$ ions were detected for every cell event. The (quasi-)simultaneous occurrence of the ion signals and the optical proof in Fig. 6 confirmed that the cells were carried within the droplets and introduced into the plasma. It furthermore corroborates the theory that the droplet undergoes a desolvation process so that a (semi-)solid particle is formed prior to the analysis in the plasma. ${ }^{22,32}$

According to the ${ }^{193} \mathrm{Ir}^{+}$ion signal, the cell events yielded a FWHM $\leq 100 \mu$ s which is in agreement with Tanner et al. ${ }^{57}$ who reported $100 \mu \mathrm{s}$. The FW base was found to be in the range of 240 to $330 \mu$ s, which is slightly shorter than the droplet-only data reported in Stewart et al. ${ }^{27}$ The total number of ion counts for a single droplet tracer ${ }^{133} \mathrm{Cs}^{+}$event was comparable to the total number of nucleus marker ${ }^{193} \mathrm{Ir}^{+}$counts. For both isotopes, the signal duration appeared to be similar. The ${ }^{31} \mathrm{P}^{+}$ion signals and the ones originating from surface markers such as ${ }^{164} \mathrm{Dy}^{+}$ (in all four cells), ${ }^{147} \mathrm{Sm}^{+}$(in cell \#3) and ${ }^{165} \mathrm{Ho}^{+}$(in cell \#2) gave rise to significantly shorter signal durations when compared to ion signals from droplets or nuclei. The latter observation is most likely explained by the significantly lower number of ion counts when compared to the nucleus marker signal which gave rise to shorter signal durations. According to the interpretation of Tanner et al., ${ }^{57}$ shattered cells or multiple fragments of cells or, alternatively, cell agglomerates could give rise to elongated transients, that means transients that last significantly longer than $300 \mu \mathrm{s}$ while showing a typical fine-structure of multiple overlapping peaks. In the latter study, transients were recorded with $\mu$ s time resolution using an oscilloscope connected to the detector analog stage preamplifier.

In general, cells that are either already fragmented or are shattered during the nebulization process would most likely be sampled into many, distinct droplets so that the detection and discrimination between intact and shattered cells would become possible. In the end, the total number of ion counts per cell (or cell fragment) event must be considered as a major limitation regarding time resolution. Increasing the time resolution means that the total number of ion counts recorded would be distributed over more time bins which increase the limit of detection. 
On the other hand, when a microdroplet generator is used, even a shattered cell could still be analyzed as all fragments would be preserved within the transporting droplet, assuming the cell damage occurred during or after droplet formation. As mentioned previously, the investigation of monodisperse droplets using a light scatter experiment (FACS) would be the method of choice in order to reveal structural information about the cells sampled, especially when the cells are transported via monodisperse droplets that are significantly larger (by at least a factor of 3 to 4 ) than the cells.

In a subsequent study, approximately 1000 mouse lung cells were measured and the single cell events were detected according to the DNA-labelled Ir content shown in Fig. 8a and according to the $\mathrm{P}$ content shown in Fig. 8c. As the cells were enriched for $\mathrm{CD} 45+$, further cell events were recorded regarding the surface marker $\mathrm{CD} 45+{ }^{164} \mathrm{Dy}^{+}$ion signal highlighted in Fig. 8b.
Note, that mouse lung cells were enriched for CD45+ positive cells and the sample contains different cell types with slightly different cell sizes. As an Ir intercalator was used to label the cell DNA present in the cell nucleus, the $\mathrm{Ir}^{+}$ion signals colored in purple can certainly be attributed to single (or multiple) cell events (Fig. 8a). The majority of the cell signals yielded 100 to 200 counts for ${ }^{193} \mathrm{Ir}^{+}$. Events exceeding 200 counts could be attributed to a double cell event, cell agglomerate or different, less abundant cell types with a higher DNA content, e.g. macrophage. ${ }^{79}$ Events that yielded less than 100 counts, could be attributed to cells with a lower DNA content, e.g. smaller cells. The events colored in gray represent the background.

As the sample was enriched, many cells were tested positively on the CD45+ marker indicated by the ${ }^{164} \mathrm{Dy}^{+}$ion signal as is shown in the correlation plot in Fig. 8b. Depending on the cell type (heterogeneous sample), a ${ }^{164} \mathrm{Dy}^{+}$ion signal between 10 to 100 counts per cell event was observed while the ${ }^{193} \mathrm{Ir}^{+}$ion signal was 100 to 200 counts for the majority of the cell events where (a)



(b)

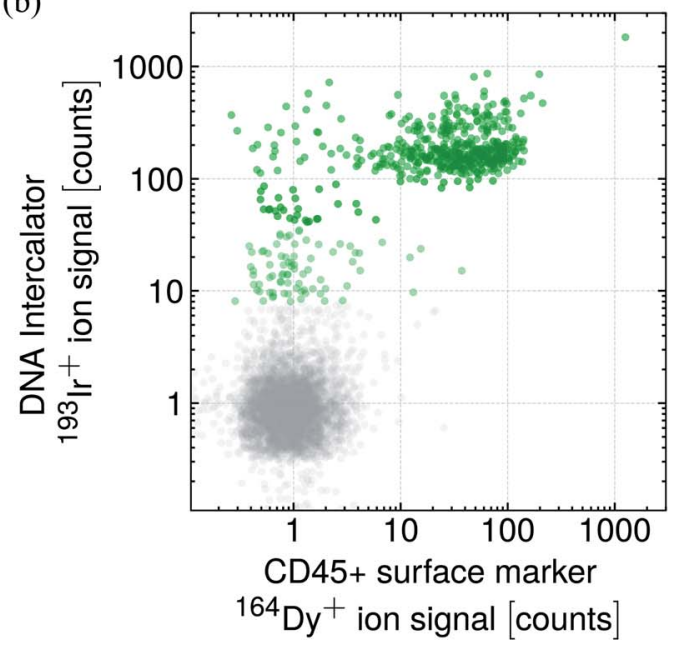

(c)



Fig. 8 Analysis of a CD45+ enriched mouse lung cell sample showing the distribution of DNA I $\mathrm{r}^{+}$ion signals (a) and the distribution of cell surface marker ${ }^{164} \mathrm{Dy}^{+}$signals versus the DNA ${ }^{193} \mid \mathrm{r}^{+}$ion signals (b). The correlation of the DNA ${ }^{193} \mid \mathrm{r}^{+}$ion signals with the ${ }^{31} \mathrm{P}^{+}$ion signals is shown in (c). Events in purple, green and brown, respectively, can be attributed to cell events. Recorded background signals were colored in gray. The cells were transported within $74 \mu \mathrm{m}$ sized droplets at a dispensing frequency of $100 \mathrm{~Hz}$. 
only few events gave rise to a higher or lower $\operatorname{Ir}^{+}$ion signal. Furthermore, some cell events were identified as such according to their DNA content, but were not tested as CD45+ positive.

The obtained ${ }^{31} \mathrm{P}^{+}$ion signals were correlated with the DNA ${ }^{193} \mathrm{Ir}^{+}$ion signal which is shown in Fig. 8c. Notably, almost all the cell events yielded ${ }^{31} \mathrm{P}^{+}$ion signals between 10 to 100 counts per cell event. Cell events yielding less than 100 counts for ${ }^{193} \mathrm{Ir}^{+}$ showed also lower ${ }^{31} \mathrm{P}^{+}$ion signals indicating a lower $\mathrm{P}$ content. As, in comparison with the other cell events, a lower DNA and P content had been obtained, the aforementioned cell events could be attributed to smaller cells. Thus, the ${ }^{31} \mathrm{P}^{+}$ion signal could be used as suitable cell event tracer, as suggested in ref. 9 and 80, and adds an additional mass channel to the evaluation process that decides whether a 'true' cell event has occurred or not.

The data points in Fig. 8 originate from one data set and the different colors should support the interpretation of the obtained cell events measured as proof of concept in a purely qualitative fashion. Therefore, well-defined thresholds, that would allow distinguishing between background and incubated cells on a quantitative base, are not provided.

In order to get a better separation of true cell events from background signals, higher instrumental sensitivity would be required which would improve the quality of the cell analysis significantly. The prototype TOF instrument used in this study provides sensitivities which are approximately one order of magnitude lower than these of a CyTOF®. Recently, new TOF instruments have been released showing a significant improvement in sensitivity, which could certainly be beneficial for future cell analysis. ${ }^{\mathbf{1}}$

\section{Conclusion and outlook}

In this work, the capabilities of a downward-pointing vertical ICP-TOFMS with respect to multielement detection of single droplets and cells were studied. The ability of recording timeresolved droplet signals confirms the observations previously reported. ${ }^{1}$ Thus, time-resolved transient signals of droplets up to $1000 \mathrm{~Hz}$ were acquired while obtaining stable element ratios. This was possible due to a modified falling-tube design that was equipped with several gas inlets and a heating system allowing the operation of the system at elevated temperatures. Droplets up to a size of $93 \mu \mathrm{m}$ were measured while the upper droplet size is currently limited by the microdroplet dispenser capabilities. It can be assumed that even larger droplets could be transported and analyzed. By optical inspection it could be demonstrated that different types of cells got sampled intact into droplets, and the transient signals obtained for mouse lung cells yielded durations of $200-400 \mu$ s (FW base) and $\leq 100 \mu \mathrm{s}$ (FWHM). The droplet-cell events were detected successfully according to their Cs droplet tracer, Ir nucleus marker, surface markers and the phosphorus content.

The TOF mass analyzer used in this study was a prototype instrument and cannot compete with sensitivities and data acquisition capabilities obtained for new generation ICPTOFMS instruments that are suitable for single cell analysis or imaging of biological samples. Nevertheless, using an ICPTOFMS enabled to demonstrate new capabilities and features of the vertical downward ICP orientation for single cell analysis. Major progress was also achieved by developing a heatable triple gas inlet falling tube setup. The instrumentation's design is considered as highly promising for future cell analysis applications implementing inkjet printing techniques or other microfluidic based technologies as is, for instance, used in state-of-the-art flow cytometry.

\section{Conflicts of interest}

The authors declare no competing financial interest.

\section{Acknowledgements}

The authors would like to thank two anonymous reviewers for their supportive and thoughtful comments that helped us to improve the manuscript. They further express sincere gratitude to Prof. Henry P. Longerich for proof-reading the manuscript. Help from Prof. Alexander Gundlach-Graham providing the LabVIEW program for processing the segmented TOF data is highly appreciated and Dr Marcel Burger, Andrea Jacobs, Prof. Bernd Bodenmiller as well as Irina Iten, Dr Malgorzata Kisielow, Prof. Manfred Kopf is thanked for providing staining compounds, cells and advisable help. Stefan Gut from the glassblowing division at University of Zurich is thanked. Dr Bodo Hattendorf, Roland Mäder and Philippe Trüssel is thanked for their support regarding the design and construction of the downward-pointing ICP-MS. The authors are grateful for the financial support from the Swiss National Science Foundation via project no. $162870 \& 197224$.

\section{References}

1 T. Vonderach, B. Hattendorf and D. Günther, New Orientation: A Downward-pointing Vertical Inductively Coupled Plasma Mass Spectrometer for the Analysis of Microsamples, Anal. Chem., 2021, 93(2), 1001-1008.

2 A. Montaser, Inductively Coupled Plasmas in Analytical Atomic Spectrometry, VCH Publishers etc., New York, New York, 2nd edn, 1992, vol. XXII, p. 1017 S.

3 J. L. Todolí and J. M. Mermet, Liquid Sample Introduction in ICP Spectrometry: A Practical Guide, 2008, pp. 1-289.

4 D. R. Wiederin, F. G. Smith and R. S. Houk, Direct Injection Nebulization for Inductively Coupled Plasma MassSpectrometry, Anal. Chem., 1991, 63(3), 219-225.

5 J. R. Chirinos, K. Kahen, S. E. O'Brien and A. Montaser, Mixed-gas inductively coupled plasma atomic emission spectrometry using a direct injection high efficiency nebulizer, Anal. Bioanal. Chem., 2002, 372(1), 128-135.

6 K. Jorabchi, R. McCormick, J. A. Levine, H. Liu, S.-H. Nam and A. Montaser, High efficiency nebulization for helium inductively coupled plasma mass spectrometry, Spectrochim. Acta, Part B, 2006, 61(8), 945-950.

7 C. S. Westphal, J. A. McLean, B. W. Acon, L. A. Allen and A. Montaser, Axial inductively coupled plasma time-offlight mass spectrometry using direct liquid sample introduction, J. Anal. At. Spectrom., 2002, 17(7), 669-675. 
8 A. S. Groombridge, S. Miyashita, S. Fujii, K. Nagasawa, T. Okahashi, M. Ohata, T. Umemura, A. Takatsu, K. Inagaki and K. Chiba, High Sensitive Elemental Analysis of Single Yeast Cells (Saccharomyces cerevisiae) by TimeResolved Inductively-Coupled Plasma Mass Spectrometry Using a High Efficiency Cell Introduction System, Anal. Sci., 2013, 29(6), 597-603.

9 S. Miyashita, A. S. Groombridge, S. Fujii, A. Minoda, A. Takatsu, A. Hioki, K. Chiba and K. Inagaki, Highly efficient single-cell analysis of microbial cells by timeresolved inductively coupled plasma mass spectrometry, $J$. Anal. At. Spectrom., 2014, 29(9), 1598-1606.

10 V. A. Fassel and B. R. Bear, Ultrasonic Nebulization of Liquid Samples for Analytical Inductively Coupled Plasma-Atomic Spectroscopy - an Update, Spectrochim. Acta, Part B, 1986, 41(10), 1089-1113.

11 N. Convery and N. Gadegaard, 30 years of microfluidics, Micro Nano Eng., 2019, 2, 76-91.

12 G. M. Hieftje and H. V. Malmstadt, A Unique System for Studying Flame Spectrometric Processes, Anal. Chem., 1968, 40(12), 1860-1867.

13 G. M. Hieftje and H. V. Malmstadt, A New Approach to Flame Spectrometric Analysis Utilizing Isolated Droplets of Sample Solution, Anal. Chem., 1969, 41(13), 1735-1744.

14 J. B. French, B. Etkin and R. Jong, Monodisperse Dried Microparticulate Injector for Analytical Instrumentation, Anal. Chem., 1994, 66(5), 685-691.

15 G. C. Y. Chan and G. M. Hieftje, Local cooling, plasma reheating and thermal pinching induced by single aerosol droplets injected into an inductively coupled plasma, Spectrochim. Acta, Part B, 2016, 121, 55-66.

16 G. C. Y. Chan and G. M. Hieftje, Effect of hydrogen isotope on plasma impedance and thermal pinching induced by single aerosol droplets injected into an inductively coupled plasma, Spectrochim. Acta, Part B, 2021, 176, 106035.

17 G. C. Y. Chan, Z. L. Zhu and G. M. Hieftje, Effect of single aerosol droplets on plasma impedance in the inductively coupled plasma, Spectrochim. Acta, Part B, 2012, 76, 87-95.

18 G. C. Y. Chan, Z. L. Zhu and G. M. Hieftje, Operating parameters and observation modes for individual droplet analysis by inductively coupled plasma-atomic emission spectrometry, Spectrochim. Acta, Part B, 2012, 76, 77-86.

19 N. C. Clampitt and G. M. Hieftje, Investigation into Mechanism of Desolvation of Sample Droplets in Flame Spectrometry, Anal. Chem., 1972, 44(7), 1211-1218.

20 P. P. Mahoney and G. M. Hieftje, Fluorometric Analysis on Individual Nanoliter Sample Droplets, Appl. Spectrosc., 1994, 48(8), 956-958.

21 M. P. Dziewatkoski, L. B. Daniels and J. W. Olesik, Time resolved inductively coupled plasma mass spectrometry measurements with individual, monodisperse drop sample introduction, Anal. Chem., 1996, 68(7), 1101-1109.

$22 \mathrm{~J}$. W. Olesik, Investigating the fate of individual sample droplets in inductively coupled plasmas, Appl. Spectrosc., 1997, 51(5), A158-A175.

23 J. W. Olesik and M. P. Dziewatkoski, Time-resolved measurements of individual ion cloud signals to investigate space-charge effects in plasma mass spectrometry, J. Am. Soc. Mass Spectrom., 1996, 7(4), 362-367. 24 J. W. Olesik and S. E. Hobbs, Monodisperse Dried Microparticulate Injector - a New Tool for Studying Fundamental Processes in Inductively-Coupled Plasmas, Anal. Chem., 1994, 66(20), 3371-3378.

25 J. W. Olesik, J. A. Kinzer and G. J. McGowan, Observation of atom and ion clouds produced from single droplets of sample in inductively coupled plasmas by optical emission and laser-induced fluorescence imaging, Appl. Spectrosc., 1997, 51(5), 607-616.

26 I. I. Stewart, C. E. Hensman and J. W. Olesik, Influence of gas sampling on analyte transport within the ICP and ion sampling for ICP-MS studied using individual, isolated sample droplets, Appl. Spectrosc., 2000, 54(2), 164-174.

27 I. I. Stewart and J. W. Olesik, Time-resolved measurements with single droplet introduction to investigate space-charge effects in plasma mass spectrometry, J. Am. Soc. Mass Spectrom., 1999, 10(2), 159-174.

28 A. C. Lazar and P. B. Farnsworth, Investigation of the analytical performance of an MDMI-ICP-AES system, Appl. Spectrosc., 1997, 51(5), 617-624.

29 A. C. Lazar and P. B. Farnsworth, Characterization of an inductively coupled plasma with xylene solutions introduced as monodisperse aerosols, Anal. Chem., 1997, 69(19), 3921-3929.

30 A. C. Lazar and P. B. Farnsworth, Matrix effect studies in the inductively coupled plasma with monodisperse droplets. Part II: the influence of matrix on spatially integrated ion density, Appl. Spectrosc., 1999, 53(4), 465-470.

31 L. A. Allen, J. J. Leach and R. S. Houk, Spatial location of the space charge effect in individual ion clouds using monodisperse dried microparticulate injection with a twin quadrupole inductively coupled plasma mass spectrometer, Anal. Chem., 1997, 69(13), 2384-2391.

32 C. C. Garcia, A. Murtazin, S. Groh, M. Becker and K. Niemax, Characterization of particles made by desolvation of monodisperse microdroplets of analyte solutions and particle suspensions for nanoparticle calibration in inductively coupled plasma spectrometry, Spectrochim. Acta, Part B, 2010, 65(1), 80-85.

33 C. C. Garcia, A. Murtazin, S. Groh, V. Horvatic and K. Niemax, Characterization of single $\mathrm{Au}$ and $\mathrm{SiO}_{2}$ nanoand microparticles by ICP-OES using monodisperse droplets of standard solutions for calibration, J. Anal. At. Spectrom., 2010, 25(5), 645-653.

34 S. Groh, C. C. Garcia, A. Murtazin, V. Horvatic and K. Niemax, Local effects of atomizing analyte droplets on the plasma parameters of the inductively coupled plasma, Spectrochim. Acta, Part B, 2009, 64(3), 247-254.

35 S. Gschwind, L. Flamigni, J. Koch, O. Borovinskaya, S. Groh, K. Niemax and D. Günther, Capabilities of inductively coupled plasma mass spectrometry for the detection of nanoparticles carried by monodisperse microdroplets, $J$. Anal. At. Spectrom., 2011, 26(6), 1166-1174.

36 J. Koch, L. Flamigni, S. Gschwind, S. Allner, H. Longerich and D. Günther, Accelerated evaporation of microdroplets 
at ambient conditions for the on-line analysis of nanoparticles by inductively-coupled plasma mass spectrometry, J. Anal. At. Spectrom., 2013, 28(11), 1707-1717.

37 O. Borovinskaya, M. Aghaei, L. Flamigni, B. Hattendorf, M. Tanner, A. Bogaerts and D. Günther, Diffusion- and velocity-driven spatial separation of analytes from single droplets entering an ICP off-axis, J. Anal. At. Spectrom., 2014, 29(2), 262-271.

38 L. Hendriks, B. Ramkorun-Schmidt, A. Gundlach-Graham, J. Koch, R. N. Grass, N. Jakubowski and D. Günther, Single-particle ICP-MS with online microdroplet calibration: toward matrix independent nanoparticle sizing, J. Anal. At. Spectrom., 2019, 34(4), 716-728.

39 L. Flamigni, J. Koch and D. Günther, The effect of carrier gas humidity on the vaporization of laser-produced aerosols in inductively coupled plasmas, J. Anal. At. Spectrom., 2014, 29(2), 280-286.

40 B. Franze, I. Strenge and C. Engelhard, Single particle inductively coupled plasma mass spectrometry: evaluation of three different pneumatic and piezo-based sample introduction systems for the characterization of silver nanoparticles, J. Anal. At. Spectrom., 2012, 27(7), 1074-1083.

41 J. O. Orlandini, V. Niessen, J. N. Schaper, J. H. Petersen and N. H. Bings, Development and characterization of a thermal inkjet-based aerosol generator for micro-volume sample introduction in analytical atomic spectrometry, J. Anal. At. Spectrom., 2011, 26(9), 1781-1789.

42 A. Gundlach-Graham and K. Mehrabi, Monodisperse microdroplets: a tool that advances single-particle ICP-MS measurements, J. Anal. At. Spectrom., 2020, 35(9), 1727-1739.

43 Y. Kaburaki, A. Nomura, Y. Ishihara, T. Iwai, H. Miyahara and A. Okino, Development of Injection Gas Heating System for Introducing Large Droplets to Inductively Coupled Plasma, Anal. Sci., 2013, 29(12), 1147-1151.

44 S. Alavi, X. Guo, S. Morteza Javid, A. Ebrahimi and J. Mostaghimi, High-Sensitivity and High-Speed SingleParticle Inductively Coupled Plasma Spectrometry with the Conical Torch, Anal. Chem., 2020, 92(17), 11786-11794.

45 A. R. Eastgate, R. C. Fry and G. H. Gower, Radiation Versus Conduction in Heated Spray Chamber Desolvation for Inductively Coupled Plasmas, J. Anal. At. Spectrom., 1993, 8(2), 305-308.

46 W. Schrön and U. Müller, Influence of heated spray chamber desolvation on the detectability in inductively coupled plasma atomic emission spectrometry, Fresenius' J. Anal. Chem., 1997, 357(1), 22-26.

47 E. Paredes, M. Grotti, J. M. Mermet and J. L. Todoli, Heatedspray chamber-based low sample consumption system for inductively coupled plasma spectrometry, J. Anal. At. Spectrom., 2009, 24(7), 903-910.

48 G. Caumette, C. P. Lienemann, I. Merdrignac, H. Paucot, B. Bouyssiere and R. Lobinski, Sensitivity improvement in ICP MS analysis of fuels and light petroleum matrices using a microflow nebulizer and heated spray chamber sample introduction, Talanta, 2009, 80(2), 1039-1043.

49 A. Al Hejami and D. Beauchemin, Infrared heating of commercially available spray chambers to improve the analytical performance of inductively coupled plasma optical emission spectrometry, J. Anal. At. Spectrom., 2018, 33(11), 2008-2014.

50 L. C. Alves, D. R. Wiederin and R. S. Houk, Reduction of Polyatomic Ion Interferences in Inductively Coupled Plasma Mass-Spectrometry by Cryogenic Desolvation, Anal. Chem., 1992, 64(10), 1164-1169.

$51 \mathrm{~J}$. W. Lam and J. W. Mclaren, Use of Aerosol Processing and Nitrogen - Argon Plasmas for Reduction of Oxide Interference in Inductively Coupled Plasma MassSpectrometry, J. Anal. At. Spectrom., 1990, 5(6), 419-424.

52 O. Ornatsky, D. Bandura, V. Baranov, M. Nitz, M. A. Winnik and S. Tanner, Highly multiparametric analysis by mass cytometry, J. Immunol. Methods, 2010, 361(1-2), 1-20.

53 F. Virani and S. Tanner, Mass Cytometry: An Evolution in ICP-MS Enabling Novel Insights in Single-Cell Biology, Spectroscopy, 2015, 30(5), 14-22.

54 A. M. Mistry, A. R. Greenplate, R. A. Ihrie and J. M. Irish, Beyond the message: advantages of snapshot proteomics with single-cell mass cytometry in solid tumors, FEBS J., 2019, 286(8), 1523-1539.

55 M. D. Leipold, E. W. Newell and H. T. Maecker, Multiparameter Phenotyping of Human PBMCs Using Mass Cytometry, Immunosenescence: Methods and Protocols, 2015, vol. 1343, pp. 81-95.

56 S. C. Bendall, G. P. Nolan, M. Roederer and P. K. Chattopadhyay, A deep profiler's guide to cytometry, Trends Immunol., 2012, 33(7), 323-332.

57 S. D. Tanner, O. Ornatsky, D. R. Bandura and V. I. Baranov, Multiplex bio-assay with inductively coupled plasma mass spectrometry: towards a massively multivariate single-cell technology, Spectrochim. Acta, Part B, 2007, 62(3), 188-195.

58 R. E. Saunders, J. E. Gough and B. Derby, Delivery of human fibroblast cells by piezoelectric drop-on-demand inkjet printing, Biomaterials, 2008, 29(2), 193-203.

59 T. Xu, J. Jin, C. Gregory, J. J. Hickman and T. Boland, Inkjet printing of viable mammalian cells, Biomaterials, 2005, 26(1), 93-99.

60 E. K. T. Er Qiang Li and S. T. Thoroddsen, Piezoelectric Dropon-Demand Inkjet Printing of Rat Fibroblast Cells: Survivability Study and Pattern Printing, arXiv, 1310.0656, 2013.

61 J. Hendriks, C. W. Visser, S. Henke, J. Leijten, D. B. F. Saris, C. Sun, D. Lohse and M. Karperien, Optimizing cell viability in droplet-based cell deposition, Sci. Rep., 2015, 5, 11304.

62 K. Shigeta, G. Koellensperger, E. Rampler, H. Traub, L. Rottmann, U. Panne, A. Okino and N. Jakubowski, Sample introduction of single selenized yeast cells (Saccharomyces cerevisiae) by micro droplet generation into an ICP-sector field mass spectrometer for label-free detection of trace elements, J. Anal. At. Spectrom., 2013, 28(5), 637-645.

63 K. Shigeta, H. Traub, U. Panne, A. Okino, L. Rottmann and N. Jakubowski, Application of a micro-droplet generator for an ICP-sector field mass spectrometer - optimization and analytical characterization, J. Anal. At. Spectrom., 2013, 28(5), 646-656. 
64 P. E. Verboket, O. Borovinskaya, N. Meyer, D. Günther and P. S. Dittrich, A New Microfluidics-Based Droplet Dispenser for ICPMS, Anal. Chem., 2014, 86(12), 6012-6018.

65 T. Vonderach, B. Hattendorf, D. Günther, utility patent, Patent Pending, 2020, WO2020187856.

66 Y. Teramoto and H. H. Kim, Size distribution measurement of microplastics using a temporally and spatially resolved inductively coupled plasma optical emission spectrometer (ICP-OES), J. Anal. At. Spectrom., 2021, 36(8), 1594-1599.

67 O. Borovinskaya, B. Hattendorf, M. Tanner, S. Gschwind and D. Günther, A prototype of a new inductively coupled plasma time-of-flight mass spectrometer providing temporally resolved, multi-element detection of short signals generated by single particles and droplets, J. Anal. At. Spectrom., 2013, 28(2), 226-233.

68 M. Schild, A. Gundlach-Graham, A. Menon, J. Jevtic, V. Pikelja, M. Tanner, B. Hattendorf and D. Günther, Replacing the Argon ICP: Nitrogen Microwave Inductively Coupled Atmospheric-Pressure Plasma (MICAP) for Mass Spectrometry, Anal. Chem., 2018, 90(22), 13443-13450.

69 A. Arp, M. Döring, W. Meyer, U. Pollmann, Mikrodosiervorrichtung, utility patent, DE10153708B4, 2004.

70 L. Hendriks, A. Gundlach-Graham, B. Hattendorf and D. Günther, Characterization of a new ICP-TOFMS instrument with continuous and discrete introduction of solutions, J. Anal. At. Spectrom., 2017, 32(3), 548-561.

71 A. Gundlach-Graham, L. Hendriks, K. Mehrabi and D. Günther, Monte Carlo Simulation of Low-Count Signals in Time-of-Flight Mass Spectrometry and Its Application to Single-Particle Detection, Anal. Chem., 2018, 90(20), 1184711855.

72 S. E. Long and R. F. Browner, Influence of Water on Conditions in the Inductively Coupled Argon Plasma, Spectrochim. Acta, Part B, 1988, 43(12), 1461-1471.
73 J. W. Olesik and S. J. Den, Effect of Central Gas-Flow Rate and Water on an Argon Inductively Coupled Plasma Spatially Resolved Emission, Ion-Atom Intensity Ratios and Electron Number Densities, Spectrochim. Acta, Part B, 1990, 45(7), 731-752.

74 J. W. Tromp, M. Pomares, M. Alvarez-Prieto, A. Cole, H. Ying and E. D. Salin, Exploration of robust operating conditions in inductively coupled plasma mass spectrometry, Spectrochim. Acta, Part B, 2003, 58(11), 1927-1944.

75 H. P. Longerich, B. J. Fryer and D. F. Strong, Determination of Lead Isotope Ratios by Inductively Coupled Plasma-Mass Spectrometry (Icp-Ms), Spectrochim. Acta, Part B, 1987, 42(12), 39-48.

76 A. Ulianov, O. Muntener and U. Schaltegger, The ICPMS signal as a Poisson process: a review of basic concepts, $J$. Anal. At. Spectrom., 2015, 30(6), 1297-1321.

77 S. Gschwind, H. Hagendorfer, D. A. Frick and D. Günther, Mass Quantification of Nanoparticles by Single Droplet Calibration Using Inductively Coupled Plasma Mass Spectrometry, Anal. Chem., 2013, 85(12), 5875-5883.

78 A. Cossarizza, et al., Guidelines for the use of flow cytometry and cell sorting in immunological studies, Eur. J. Immunol., 2017, 47(10), 1584-1797.

79 H. M. McGuire and T. M. Ashhurst, Mass Cytometry Methods and Protocols Preface, Methods Mol. Biol., 2019, 1989, 13-31.

80 M. Corte-Rodríguez, E. Blanco-Gonzalez, J. Bettmer and M. Montes-Bayon, Quantitative Analysis of Transferrin Receptor 1 (TfR1) in Individual Breast Cancer Cells by Means of Labeled Antibodies and Elemental (ICP-MS) Detection, Anal. Chem., 2019, 91(24), 15532-15538.

81 A. Gundlach-Graham, Multiplexed and multi-metal singleparticle characterization with ICP-TOFMS, Comprehensive Analytical Chemistry, 2021, 93, 69-101. 